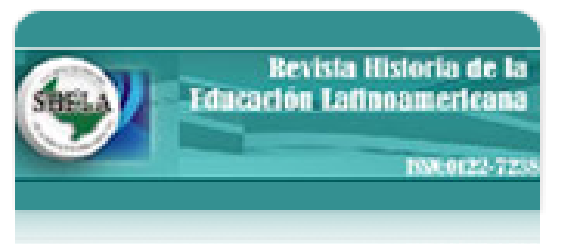

Revista Historia de la Educación Latinoamericana

ISSN: 0122-7238

rhela@uptc.edu.co

Universidad Pedagógica y Tecnológica de

Colombia

Colombia

Cammarota, Adrián

EL MINISTERIO DE EDUCACIÓN DURANTE EL PERONISMO: IDEOLOGÍA, CENTRALIZACIÓN, BUROCRATIZACIÓN Y RACIONALIZACIÓN ADMINISTRATIVA (1949-1955)

Revista Historia de la Educación Latinoamericana, vol. 15, 2010, pp. 63-92

Universidad Pedagógica y Tecnológica de Colombia

Boyacá, Colombia

Disponible en: http://www.redalyc.org/articulo.oa?id=86918064004

Cómo citar el artículo

Número completo

- Más información del artículo

Página de la revista en redalyc.org

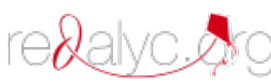

Sistema de Información Científica

Red de Revistas Científicas de América Latina, el Caribe, España y Portugal Proyecto académico sin fines de lucro, desarrollado bajo la iniciativa de acceso abierto 


\title{
EL MINISTERIO DE EDUCACIÓN DURANTE EL PERONISMO: IDEOLOGÍA, CENTRALIZACIÓN, BUROCRATIZACIÓN Y RACIONALIZACIÓN ADMINISTRATIVA(1949-1955)
}

\author{
Adrián Cammarota ${ }^{1}$ \\ Universidad Nacional General - Argentina \\ Grupo de Investigación HISULA \\ adriancammarota2000@yahoo.com.ar
}

Recepción: 26/02/2010

Evaluación: 15/06/2010

Aceptación: 12/11/2010

Artículo de Reflexión

\section{RESUMEN}

El artículo analiza la génesis del Ministerio de Educación en el año 1949 durante los designios del primer gobierno peronista. Son estos años en los cuales se evidencia la necesidad de centralizar el sistema de enseñanza y se implementan políticas de racionalización administrativa. Estas medidas se encuentran entrecruzadas con la imposición de la ideología oficial en un contexto de democratización de los derechos sociales.

Palabras clave: Estado, Educación, Ideología, Centralización, Burocracia, Pedagogía.

\footnotetext{
1 Doctorando en Ciencias Sociales, Instituto de Desarrollo Económico y SocialUniversidad Nacional General Sarmiento (IDES-UNGS). Magíster y Licenciado en Historia por la Universidad Nacional de Tres de Febrero. Integra el proyecto Ubacyt GEF (2010-2012). Trabajo y Salud en la Argentina: saberes académicos y políticos (1915-1955)". Unidad de Trabajo: Instituto de Historia de la Medicina. Facultad de Buenos Aires. Universidad de Buenos Aires. Su tesis de doctorado está siendo dirigida por la Dra. Karina Ramacciotti, finalmente es integrante del grupo de investigación Historia y Prospectiva de la Universidad Latinoamericana - HISULA.
} 


\title{
THE DEPARTMENT OF EDUCATION DURING THE PERONISMO: IDEOLOGY, CENTRALIZATION, BUROCRAZY AND ADMINISTRATIVE RATIONALIZATION (1949-1955)
}

\author{
Adrián Cammarota \\ Universidad Nacional General - Argentina \\ HISULA Research Group \\ adriancammarota2000@yahoo.com.ar
}

\begin{abstract}
The article analyses the Ministry of Education genesis in the year of 1949 during the designees of the first Peronista government, during these years to demonstrate the need to centralize the system of education and the politics of administrative rationalization and imposition of the official ideology in a context of democratization of the social rights.
\end{abstract}

Key words: State, Education, Ideology, Centralization, Bureaucracy, Pedagogy. 


\section{INTRODUCCIÓN}

El presente trabajo analiza la conformación del Ministerio de Educación Nacional en el año 1949. Esta creación institucional se produjo durante los años del llamado primer peronismo (1946-1955). Es durante este período que se implementan políticas de racionalización y burocratización de las diferentes agencias estatales. A partir de 1952 dichas medidas se combinan con una acentuación del control ideológico y de medidas que impulsaron una reducción de gastos.

La transformación y la modernización de la maquinaria administrativa se entroncaron con el advenimiento del Estado peronista ${ }^{2}$ siguiendo los lineamientos del Primer Plan Quinquenal (1947-1952). Se ensambló un organismo burocrático con técnicos administrativos para controlar todas las cuestiones referentes al campo de la enseñanza. El objetivo era la centralización del sistema de instrucción que se hallaba, hasta ese momento, fragmentado en dispares sistemas.

Existe un relativo vacío historiográfico a la hora de encarar el estudio de las instituciones estatales en Argentina. Los diferentes tipos de abordajes que se han desplegado en referencia a la educación durante el peronismo no han centrado la mirada sobre el funcionamiento del Ministerio de Educación. Se hallan referencias colaterales que remiten a la "politización de la educación," 3 a los "discursos pedagógicos de la época", a "las reformas del sistema educativo", a "la relación entre cultura política y educación"4 y a la interacción entre la Iglesia Católica, el peronismo y la enseñanza en general. ${ }^{5}$ En otro plano, la historiadora Silvina Gvirtz indagó sobre la respuesta que brindaron los docentes a la inclusión de la doctrina justicialista en los contenidos escolares. ${ }^{6}$

2 GONZALEZ BOLLO, Hernán. (2007): "Paradojas de la capacidad estatal bajo el peronismo: la centralización estadística y el Cuarto Censo Nacional, entre el caos burocrático y la manipulación de datos, 1943-1947". Ponencia presentada en las XI Jornadas Interescuelas/Departamento de Historia. Tucumán, 19 al 22 de septiembre.

3 PLOTKIN, Mariano. (1994): Mañana es San Perón: Propaganda, rituales políticos y educación en el régimen peronista, Buenos Aires, Ariel. WAINERMAN, Catalina y HEREDIA Mariana. (1998): ¿Mamá amasa la masa? Cien años en los libros de lectura de la escuela primaria, Buenos Aires, Editorial Belgrano, 1998, p. 35.

4 BERNETTI Jorge Luis y PUIGGRÓS Adriana (dirección). (2006): Peronismo, Cultura Política y educación (1945-1955), Buenos Aires, Galerna, p. 56.

5 CAIMARI, Lila. (1995): Perón y la Iglesia Católica. Religión, Estado y sociedad en la Argentina, 1943-1955, Buenos Aires, Ariel. BIANCHI Susana. (1996):"Catolicismo y peronismo: la educación como campo de conflicto", en Anuario del Instituto de Estudios Históricos-Sociales, $\mathrm{n}^{\circ}$ 11, pp.147-178.

6 GVIRTZ, Silvina. (1999): "La politización de los contenidos escolares y la respuesta de los docentes primarios en los primeros gobiernos de Perón- Argentina 1949-1955", en Estudios Interdisciplinarios de América Latina y el Caribe, volumen 10, $\mathrm{n}^{\circ} 1$, enerojunio, pp. 112-140.

Rev. hist. edu. latinoam. Vol. 15. Año 2010, pp. 63 - 92 
Otros aportes han escudriñado los mecanismos que primaron en el ideario planificador de la época, signado por una problemática tensión entre racionalidad, neutralidad tecnocrática y concentración de poder. ${ }^{7}$ La relación entre los profesionales y el Estado y el lugar protagónico que le otorgaron a ese sector en el cuerpo de las instituciones argentinas, constituyó el eje de análisis de los últimos años. ${ }^{8}$ En este escenario, la historiadora Karina Ramacciotti nos lleva a dilucidar, entre otras cuestiones, la acción del Estado en el armazón institucional que dio origen a la Secretaría de Salud Pública -con rango de ministerio a partir de 1949- centrándose en la figura del neurocirujano Ramón Carrillo. ${ }^{9}$

Este trabajo se nutre de los aportes anteriormente bosquejados y se propone analizar las causas que motivaron la constitución del Ministerio de Educación Nacional. Asimismo, se revisa su injerencia en el proceso de centralización educativa que había despuntado a fines del siglo XIX. En un plano central se destaca como dicho proceso terminó aunándose, a partir del año 1952, a un fenómeno de abierta politización del sistema de enseñanza en consonancia con el Plan deAusteridad y el Segundo Plan Quinquenal (1952-1957). La joven burocracia ministerial y la comunidad educativa -docentes, directivos y alumnos- se vieron interpelados y comprometidos por el Estado en un conjunto de medidas de racionalización de recursos y de control ideológico. A su vez, se concedió un marco profesional al trabajo de los educadores ausente en las décadas anteriores. Los docentes se transformaron en los receptores de un conjunto de derechos y garantías para nada desdeñables y que aún perduran en la actualidad.

Por un lado, una de las fuentes que inspiró este trabajo es el Boletín de Comunicaciones - publicación oficial del Ministerio de Educación- que comenzó a ser editado en el año 1949. El caudal de información que alberga en sus páginas abre las compuertas a distintas líneas de investigación. Por otro lado, el análisis propuesto es tributario de una investigación precedente en la cual se estudió la fundación de un Colegio Nacional en el distrito de Morón (Provincia de Buenos Aires) en 1949. Una parte del corpus documental está compuesto por las notas

\footnotetext{
7 BERROTARÁN, Patricia. (2004): "La planificación como instrumento: políticas y organización en el estado peronista (1946-1949)", en Sueños de Bienestar en la Nueva Argentina. Estado y Políticas Públicas durante el peronismo (1946-1955), BERROTARÁN Patricia, JÁUREGUI Aníbal y ROUGIER, Marcelo (edit), Buenos Aires, Imago Mundi, pp.15-45.

8 BIERNAT Carolina. (2007): ¿Buenos o útiles? La política inmigratoria del peronismo, Buenos Aires, Biblos. PLOTKIN Mariano y NEIURBUG Federico (compiladores) (2004): Intelectuales y expertos. La constitución del conocimiento social en la Argentina, Buenos Aires, Paidós. PALERMO Silvana. (2007): "Elite técnica y Estado liberal: la creación de una administración moderna en los Ferrocarriles del Estado (1870-1910)" en Estudios Sociales, $\mathrm{n}^{\circ} 30$.

9 RAMACCIOTTI, Karina. (2009): La política sanitaria del peronismo, Buenos Aires, Biblos, p. 45.
} 
enviadas por padres y alumnos (nas) al Ministerio de Educación halladas en el archivo de la institución citada. Por último, resta subrayar que existe una deuda pendiente en cuanto a programar la tarea de investigación hacia los archivos de los distintos Colegios Nacionales, Liceos o Escuelas Normales de la época. Dicho camino nos brindaría una visión mucho más compleja y heterogénea, en tren de apuntalar el impacto de la política educativa que emanaba de la repartición central en el conjunto de las provincias. ${ }^{10}$

\section{Hacia la centralización del sistema de enseñanza}

Acorde a las políticas de planificación estatal surgidas después de la Segunda Guerra Mundial (1939-1945) en los países capitalistas, el peronismo enarboló sus objetivos de planificación en el período 1945-1951 por medio del Plan de Gobierno. Para llevar adelante la empresa de centralización y coordinación de las cuestiones vinculadas a la esfera económica, financiera y social, se creó la Secretaría Técnica de la Nación. Pero también se fundaron nuevas áreas como el Ministerio de Educación (1949), separado del Ministerio de Justicia e Instrucción Pública tornándose, a su vez, en un área independiente. El otrora Consejo Nacional de Educación había sido intervenido por el gobierno militar que tomó el poder en 1943 convirtiéndose en un apéndice del Ministerio de Justicia. Hasta la reforma constitucional de 1949 no fue posible crear un ente independiente ya que sobrepasaba el número fijo de ministerios establecidos por la Constitución Nacional. Con la reforma, el número se incrementó de cinco a ocho ministerios. También se suprimió la Dirección General de Escuelas y Cultura y los Consejos Escolares. De esta forma se buscaba establecer una acción más directa entre el gobierno y las escuelas. ${ }^{11}$

El afán por centralizar el sistema de enseñanza se debía no sólo al espíritu reinante en el mundo de posguerra, cuya lógica bregaba decididamente por la intervención del Estado en el cuerpo social. Dos cuestiones de vital relevancia reclamaban una solución inmediata: por un lado, las limitaciones presupuestarias que sufrían las provincias para organizar su enseñanza primaria y secundaria. Por el otro, la fragmentación del sistema educativo que desde fines del siglo XIX constituyó un problema acuciante para el Estado Nacional, erigiéndose como un obstáculo a la necesidad "educar y nacionalizar" al inmigrante. ${ }^{12}$

\footnotetext{
${ }^{10}$ Una aproximación bien documentado sobre esta cuestión podemos encontrarla en PUIGGRÓS, Adriana (dirección). (2001): La Educación en las Provincias y Territorios Nacionales (1885-1945), Buenos Aires, Galerna.

${ }^{11}$ PLOTKIN. (1998): óp., cit, p. 164.

12 BERTONI, Lilia Ana. (2001): Patriotas, cosmopolitas y nacionalistas. La construcción de la nacionalidad argentina a fines del siglo XIX, Buenos Aires, Fondo de Cultura Económica. Con respecto a la preocupación del Estado y los debates médicos en torno a la higiene y las enfermedades ver ARMUS, Diego (2007): La ciudad impura: salud, tuberculosis y cultura en Buenos Aires, 1870-1950, Buenos Aires, Edhasa, p. 123.
} 
La coexistencia de escuelas particulares o privadas condujo a la coexistencia de cuatro sistemas educativos paralelos: sistema público-provincial, público-privado; sistema nacional-provincial-nacional privado. En 1884 había 13 provincias y una jurisdicción nacional, 14 sistemas educativos públicos y hasta 14 subsistemas particulares o privados. Durante las tres décadas siguientes la situación no se modificó sustancialmente. Pero, dentro de esta fragmentación, hay que destacar que en el período 1930-1945 el avance educacional en el nivel primario estuvo en manos casi totalmente del Estado. Más de la mitad de la matrícula de la educación primaria de las provincias correspondía al gobierno central gracias a las llamadas escuelas Láinez. ${ }^{13}$ El crecimiento de la enseñanza media, a diferencia del registrado en el nivel primario, contó con una fuerte participación privada dependiente de la Iglesia Católica. Sus esfuerzos estuvieron dirigidos a controlar las modalidades clásicas, especialmente el magisterio, por el rol destacado que se les otorgaban a las maestras en su misión de educar al ciudadano. ${ }^{14}$

Recién con el advenimiento del peronismo dicha problemática será revertida por la puesta en marcha de una maquinaria burocrática-educativa. Se democratizó el ciclo secundario y universitario que otrora eran reductos académicos monopolizados por una elite urbana. A su vez, se impulsó un conjunto de medidas para disminuir el analfabetismo en los sectores más postergados.

¿Cuáles fueron las herramientas implementadas para potenciar el proceso reseñado? Básicamente la fundación de nuevos establecimientos para evitar el aislamiento geográfico y albergar a los jóvenes que anhelaban seguir sus estudios secundarios. La acción distributiva del Estado permitió a un conjunto crecientes de familias enviar a sus hijos a obtener una titulación académica. El otorgamiento de becas estudiantiles también se puede mencionar como uno de los pilares constitutivos del sistema.

Hacia 1950 se crearon nuevas Escuelas Nacionales de Comercio, Secciones Comerciales y divisiones de primer año dependientes del Ministerio de Educación. Asimismo se impulsó la concreción de 39 divisiones de primer año, 19 Colegios Nacionales, 6 escuelas Nacionales de Comercio y 27 escuelas Nacionales de Comercio. ${ }^{15}$ En su mayoría estos nuevos establecimientos y divisiones se

\footnotetext{
${ }^{13}$ La Ley Lainez de 1905 autorizaba al gobierno Nacional a establecer escuelas en aquellas provincias que lo solicitaban ya sea escuelas elementales, infantiles, mixtas o rurales. Las provincias carecían de los recursos necesarios para fundarlas, por lo tanto, la Nación se haría cargo de instrumentar la enseñanza primaria con planes de estudio a fines al gobierno central.

14 TEDESCO, Juan Carlos. (2009): Educación y sociedad en la Argentina (18801945), Buenos Aires, Siglo XXI, pp. 233-235.
} 
fundaron en Capital Federal y la Provincia de Buenos Aires. ${ }^{16}$ Es probable que esta situación no respondiera únicamente a la concentración de población en esas regiones, sino también a un entramado de relaciones políticas con gobernadores e intendentes que permitía al Estado peronista avanzar sobre las autonomías provinciales.

Hay que destacar que la oferta del Estado fue mucho más innovadora en el sistema de enseñanza técnica la cual tuvo una gran expansión e inversión. El desarrollo de esta modalidad irrumpió en la década de 1930 con la adopción de un modelo basado en el crecimiento industrial. Fundamentalmente el empleador de los egresados de dichas escuelas era el Estado. Como ha señalado Tedesco, el estímulo a los estudios técnicos en los años precedentes al peronismo, no fue contradictorio con el tradicionalismo ideológico representado por la derecha política argentina. En el centro de este universo los estudios humanísticos quedaron reservados a una elite. La enseñanza práctica fue revalorizada bosquejando nuevas alternativas educativas con las escuelas de continuación: las técnicas de oficios, creadas para cubrir las demandas de los grandes centros industriales, y las escuelas de artes y oficios que brindaban cursos de cuatro años de duración orientadas hacia la mecánica, la herrería y la carpintería. ${ }^{17}$ Así las cosas, en la etapa peronista solo quedaba profundizar el proceso de industrialización para satisfacer la creciente demanda de materias primas en el viejo continente.

\section{El Ministerio de Educación: burocratización y centralización}

El Ministerio se estructuró sobre un conjunto de Direcciones Generales, Departamentos y Secciones. Las mismas fueron modificadas a partir a partir

\footnotetext{
15 Boletín de Comunicaciones, año II, $\mathrm{n}^{\circ}$ 107, 17 de marzo de 1950, pp. 110-113.

${ }^{16}$ En 1952 la nómina alcanzó a: Colegios Nacionales y Liceos de Señoritas: Colegio Nacional de Arrefices (Buenos Aires), Colegio Nacional de Coronel Dorrego (Buenos Aires), Colegio Nacional de Lanús (Buenos Aires), Colegio Nacional de Vicente López (Buenos Aires), Colegio Nacional de Huinca Renancó (Córdoba), Colegio Nacional Laboulaye (Córdoba), Colegio Nacional de Río Tercero (Córdoba), Colegio Nacional de Casilda (Santa Fe), Colegio Nacional de Ceres (Santa Fe). Escuelas Nacionales de Comercio: Sección Comercial Anexa al Colegio Nacional de Coronel Dorrego (Buenos Aires), Sección Comercial Anexa al Colegio Nacional de Lanús (Buenos Aires), Escuela Nacional de Comercio de San Urbano (Santa Fe). Escuelas Industriales de la Nación: Escuela Industrial de la Nación ${ }^{\circ}$ 10- Ciclo Superior (Capital Federal), Escuela Industrial de la Nación- Ciclo Básico- de Chacabuco (Buenos Aires), Escuela Industrial de la NaciónCiclo Básico- de Bariloche, Territorio Nacional de Río Negro. Escuelas Industriales Regionales Mixtas de la Nación: Escuela Industrial Regional Mixta de la Nación -Ciclo Básico- de San José de la Esquina, (Santa Fe). Escuelas Profesionales de Mujeres: Escuela Nacional Profesional de Mujeres de Paraná (Entre Ríos), Escuela Nacional Profesional de Mujeres de San Juan, Escuela Nacional Profesional de Mujeres de Santa Fe. Boletín de Comunicaciones, Año IV, no 227, 27 de junio de 1952, p. 506.

17 TEDESCO, Juan Carlos. (2009): Op., cit, pp. 213-219.
} 
del año 1952 producto de la crisis económica por la cual atravesaba el país. El ministro era elegido directamente por el Poder Ejecutivo Nacional. La laberíntica estructura se correspondía con la idea de planificación estatal de posguerra. El peronismo había aplicado estas recetas de optimización de recursos en otros ministerios. Al igual que en las áreas de salud, obras públicas, FFAA y previsión social, se encomendó a un grupo de técnicos la misión de relevar, analizar y procesar todos los datos referidos a la cuestión educativa con la finalidad de delinear un plan de acción. La búsqueda de eficiencia, racionalidad y control en todas las áreas mencionadas perseguía, en un principio, la consolidación de un equipo competente. Sin embargo, hay que destacar que sus consecuencias fueron más allá de dicho objetivo: se transformaron en sutiles instrumentos de control ideológico de los funcionarios estatales. ${ }^{18}$

A modo de ejemplo tomaremos para su descripción la Dirección General de Enseñanza Secundaria, Normal, Especial y Superior dependiente de Ministerio de Educación. Esta dirección sufrió una serie de modificaciones a partir del Plan de Austeridad implementado en 1952 como paliativo de la crisis económica, tema que más adelante retomaremos. El nuevo Reglamento Orgánico establecía la competencia de cada organismo. A juzgar por las directivas emitidas existía una preocupación latente con respecto a la "racionalización y división del trabajo" para que cada empleado "pudiera cumplir eficazmente con su tarea".

En la cúspide de la jerarquía se hallaba la Dirección General cuya función era "el gobierno administrativo, disciplinario y didáctico de los establecimientos de su dependencia." ${ }^{19}$ Un Director General se encargaba de la actividad de dicho organismo y de velar por los designios burocráticos. Su responsabilidad estaba sujeta a las distintas disposiciones del Reglamento, entre las cuales se encontraban la distribución del personal dentro de las dependencias para evitar el ocio en horas de trabajo e instruir a los empleados sobre el sentido de la "delegación de funciones" y de la "delegación de responsabilidades". Poseía autoridad para proponer reformas reglamentarias de organización, velar por la disciplina del personal administrativo y docente e imponer sanciones inmediatas en caso de que alguna situación la ameritase. El Director General se hallaba asistido por un Subdirector.

El Departamento Técnico era el asesor del Director General en las tareas de planificación y racionalización de las actividades de la propia Dirección

\footnotetext{
18 BERROTARÁN, Lilia Ana. (2004): Op., cit p. 33-39.

19 Boletín de Comunicaciones, Año VII, $\mathrm{n}^{\circ} 246,7$ de noviembre de 1952, pp. 11051114. Abarcaban los siguientes establecimientos: Colegios Nacionales, Colegios Nacionales para señoritas, Colegios Nacionales de Comercio, Colegios Nacionales Normales, Colegios Nacionales Regionales, Departamento de Aplicación, Jardines de Infantes e Institutos Nacionales del Profesorado).
} 
General o de la Enseñanza Secundaria, Normal y Especial. También intervenía en la organización de la educación, la creación de nuevos establecimientos o nuevas especialidades; los problemas de la orientación vocacional y el perfeccionamiento del docente. Tenía a su cargo el desarrollo y mejoramiento de los planes y programas y la consideración sobre las cuestiones relativas a los medios materiales para el desenvolvimiento óptimo del ciclo lectivo (edificios, laboratorios, talleres, equipos, moblaje, etc).

La función de coordinación y contralor correspondían a un conjunto de oficinas con unidad funcional: el Despacho. Era la encargada del estudio y tramitación de los asuntos de competencia de la Dirección General. Existían secciones administrativas y técnicas administrativas como la oficina de "Recepción y Distribución" que constituía el nexo entre la Mesa General de Entradas y Salidas y el Archivo del Ministerio y la Dirección General. Sus atribuciones eran genuinamente amplias: recibir los asuntos sometidos a consideración de la Dirección General, preparar antecedentes, informes, estudios y proyectos sobre aspectos administrativos o técnicos, entre otras cosas. La organización del Despacho de la Dirección estaba compuesto en secciones y oficinas: 1-Jefatura, 2-Subjefaturas, 3- Secciones: a) Estudio y Redacción, b) Revisión, c) Organización y Racionalización; d) Información; e) Personal e Inventario; f) Didáctica. El sector Oficinas se hallaba dividido en: a) Recepción y Distribución; b) Dactilógrafos, e) Secretaría. ${ }^{20}$

Todo asunto vinculado al desarrollo y ejecución de la enseñanza dependía de las secciones Técnico-Didácticas a cargo de un funcionario. Los jefes de estos organismos detentaban atribuciones diversas como analizar "las reacciones positivas, negativas o neutras que provoquen los planes de estudio en los educandos."

Por último, existía una Inspección General integrada por un Inspector General constituida por subinspectores de Bachillerato, Enseñanza Normal y Profesorado, Enseñanza Comercial, Inspectores docentes e Inspectores administrativos. En líneas generales, la función de este cuerpo burocrático tendía al control de la actividad pedagógica y asegurar la normalidad de las actividades en los establecimientos.

La Mesa General de Entradas recibía los expedientes con asuntos a resolver elevados por padres, alumnos y docentes.

${ }^{20}$ Boletín de Comunicaciones, Año IV, n³06, 31 de diciembre de 1953, pp. 13911395.

Rev. hist. edu. latinoam. Vol. 15. Año 2010, pp. 63 - 92 
La División Archivo enviaba al Archivo General de la Nación los expedientes acumulados con más de veinte años de antigüedad. Previamente se seleccionaba aquella documentación que, por su valor histórico, merecía ser atesorada para la posteridad. Estos documentos se referían a intereses patrimoniales del ministerio, creación, nominación y clausuras de establecimientos; resoluciones y disposiciones de carácter general normativo y actuaciones formadas en caso de ética o moral administrativa. La División Archivos quedaba autorizada- lamentablemente para el oficio del historiadorpara destruir la documentación referida a licencias, turno de vacaciones; justificación de inasistencias, presentaciones a concursos para ocupar cargos vacantes y pedidos de alumnos o profesores (becas, reincorporaciones, traslados y permutas). Los expedientes debían ser destruidos cortándolos a la mitad y, en pos de cumplir con el programa de austeridad, se debía proceder a realizar su venta "como papel usado."

Otra de las transformaciones fue la división del país por zonas de inspección en el año 1951. Cada zona quedó constituida por dos inspectores administrativos que efectuaban visitas periódicas de inspección y arqueo de los establecimientos. ${ }^{21}$

Dentro de esta estructura burocrática encontramos la Dirección de Enseñanza Religiosa que formaba parte del despacho técnico docente administrativo del Ministerio. Le correspondía la orientación, la dirección y la inspección de la enseñanza religiosa y moral. Poseía diversas atribuciones como aprobar los textos de lectura y otorgar a los profesores aspirantes al cargo el número de registro de la autorización Eclesiástica. El director de este organismo era un funcionario con dependencia inmediata del Ministro. En virtud de ello, la autonomía de esta Dirección era relativamente nula. Toda edición de carácter científico, didáctico, artístico o cultural debía llevar la aprobación del Ministerio de Educación. Poseía una estructura de organización similar al Despacho: Director, Subdirector, Departamento Técnico, e Inspección General.

Hay que subrayar que la enseñanza religiosa constituyó uno de los pilares de los discursos pedagógicos durante el primer peronismo. Sus antecedentes se remontan a la Reforma Educativa realizada por médico filofascista Manuel Fresco durante su gobernación en la provincia de Buenos Aires (1936-1939), en consonancia con el clima de ideas y sensibilidades que circulaban en el territorio nacional en la década de 1930. Fue impuesta por los sectores próximos al tradicionalismo católico y aquellos grupos nacionalistas que habían importado

${ }^{21}$ Boletín de Comunicaciones, Año II, $\mathrm{n}^{\circ}$ 167-168, 18 de mayo de 1951, pp. 421-423. 
el fascismo italiano. Estos sectores habían tomado el control de la educación, con el fin de desplazar el carácter laico del sistema de enseñanza ensamblado a fines del siglo XIX.22

La enseñanza religiosa se implementó a nivel nacional tras el golpe de Estado del 4 de junio de 1943. Asimismo, el Estado Nacional otorgaba una opción dual en cuanto a la formación espiritual de los jóvenes. Un estudiante estaba en condiciones de elegir entre las asignaturas "Moral" o "Religión". Hacia 1946, el 97, $4 \%$ de los niños matriculados en escuelas dependientes del Consejo Nacional de Educación recibió educación religiosa. Sólo el 4,6 \% de los estudiantes matriculados en escuelas oficiales recibieron educación moral en la ciudad de Buenos Aires. ${ }^{23}$

En este aspecto el peronismo mantuvo una continuidad apoyando la instrucción religiosa en las escuelas públicas, tanto en el nivel primario como en el ciclo secundario. Tras la crisis generada entre el Estado y la Iglesia Católica en la segunda presidencia peronista, la Dirección de Enseñanza Religiosa quedó literalmente suspendida el 14 de abril de 1954. Mediante una resolución se eliminaron las materias "Religión" y "Moral", siendo reemplazadas por los "Consejeros Espirituales" reclutados en el seno de la Fundación Eva Perón. ${ }^{24}$

El Consejo Gremial de Enseñanza Privada se hallaba regido por doce miembros elegidos por el Poder Ejecutivo. En teoría, las reformas implementadas en el sector privado de la educación recaían en dicho organismo. Pero en la práctica, eran los designios gubernamentales -más específicamente el Poder Ejecutivo Nacional- el que orquestaba los cambios dentro del sistema de instrucción particular alejándose, a simple vista, del paradigma democrático que en teoría representaba el sindicalismo.

Por su parte, la Dirección General de Enseñanza Técnica y la Dirección General de Primaria sostuvieron el mismo armazón burocrático que la Dirección de Enseñanza Secundaria. Como ha destacado Ramacciotti en su análisis sobre la Secretaria de Salud Pública, "la burocratización fue considerada la mejor forma por medio de la cual los profesionales podían organizarse técnicamente." ${ }^{25}$ Podemos agregar que la perentoria necesidad de centralizar el sistema no cuadraba con otro modo de concebir el proceso por fuera de los

\footnotetext{
22 CAIMARI, Lilia. (1995): Perón y la Iglesia Católica. Religión, Estado y sociedad en la Argentina, 1943-1955, Buenos Aires, Ariel p.142.

${ }^{23}$ PLOTKIN. (1994):op., cit, p. 153.

${ }^{24}$ CAIMARI. (1995): op., cit, pp.185-187.

${ }^{25}$ RAMACCIOTTI. (2009): op., cit, p 70.
} 
marcos directivos de la órbita estatal. Lamentablemente, carecemos de investigaciones para reconstruir las opiniones vertidas por el espectro político y la opinión pública de las provincias con respecto a las aspiraciones centralistas del peronismo.

\section{El Boletín de Comunicaciones (1949-1955)}

Uno de los pilares en el cual se basó la Secretaria Técnica para la planificación fue la elaboración de un conjunto de estadísticas que permitían proponer políticas a futuro. Siendo que la estadística tiene un carácter estatal y de ciencia burocrática y que responde a una imagen discursiva y estructurada, ${ }^{26}$ el peronismo no fue menos en estas cuestiones. El Boletín de Comunicaciones era una de las herramientas diseñadas para dar a conocer todos los actos de gobierno y analizar cuantitativamente y cualitativamente las cuestiones referidas al sistema de enseñanza. En sus páginas subyace la imagen de una Argentina irredenta, pautando una continuidad entre los eventos históricos que forjaron la Nación y la realidad que el gobierno intentó proyectar sobre la sociedad civil.

Por medio del Boletín, los establecimientos educativos se notificaban de las novedades emanadas del gobierno: decretos, resoluciones, nuevos programas, directivas al personal. Desde sus orígenes, estuvo surcado por un fuerte contenido político cuyo tópico más recurrente fue el nacionalismo que tendía a enaltecer la obra del gobierno. Las resoluciones ministeriales publicadas no sólo hacían referencia al aspecto pedagógico: el Ministerio de Educación "invitaba” a sus empleados y obreros del Ministerio a participar en los actos conmemorativos del 17 de Octubre ("Semana de la Lealtad") ${ }^{27}$ o a la colaboración con dinero en efectivo para la Fundación Eva Perón. ${ }^{28}$ Así, el sesgo político convive con estadísticas de distintas referencias (presupuestos anuales, cantidad de matrícula en los distintos niveles educativos, construcción de nuevos establecimientos, otorgamiento de becas y distinciones). Otro de los canales que utilizó el Ministerio de Educación para brindar información de sus actividades fue el Noticiero Radial que transmitía todos los días hábiles por L.R.A., Radio del Estado y L.S. 11, Radio Provincia de Buenos Aires.

Cada movimiento o traslado del personal docente al nivel nacional era editorializado para dar informe a las instituciones educativas del arribo del nuevo personal y la situación de revista del docente designado (titular, provisorio o

${ }^{26}$ OTERO, Hernán. (2006): Estadística y Nación. Una historia conceptual del pensamiento censal de la Argentina moderna 1868-1914, Buenos Aires, Prometeo, p.14 y 21.

${ }^{27}$ Boletín de Comunicaciones, Año II, 20 de octubre de 1950, n ${ }^{\circ}$ 139, p. 1150.

${ }^{28}$ Boletín de Comunicaciones, Año II, 3 de noviembre de 1950, n¹41, p. 1226. 
suplente). Todo lo reseñado hasta aquí se corresponde al aspecto organizativo pero, ¿cuál era ideología que tiñó la estructura burocrática ministerial? ¿Quiénes fueron los individuos que condujeron estos aspectos organizativos y quiénes ensamblaron una visión pedagógica particular?

\section{Pedagogos y Ministros: el "staff del Ministerio"}

Como han destacado los investigadores Federico Neiburg y Mariano Plotkin, una de las características del Estado en la Argentina fue y sigue siendo la convergencia de agentes sociales e instituciones con tradiciones e intereses dispares. En diversas ocasiones, los ministerios del gobierno fueron consagrados a los especialistas que trabajan en y para el Estado -los denominados técnicospor su especialización y entrenamiento académico. El término se generalizó después de la segunda posguerra bajo el compás de las ciencias sociales reinantes en EEUU. Los técnicos comparten una práctica profesional -son juristas, médicos y abogados- y poseen conocimientos especializados basados en el uso exclusivo de una jerga propia adquirida y legitimada en el mundo académico. ${ }^{29}$

El Ministerio de Educación de la Nación y el sistema educativo estructurado en la etapa peronista no estuvo exento de estas características. Pedagogos y funcionarios convivieron aunando una visión particular del sistema de enseñanza en la que se entrecruzaron el nacionalismo católico, el higienismo, el "mejoramiento de la raza" y la educación moral basada en las "vidas ejemplares" o "arquetipos humanos." 30 La tríada religión, moral y nacionalidad remitía a la conjunción de una serie de tópicos valuados en las décadas anteriores bajo la hegemonía de los conservadores. Este eclecticismo no debe sorprender al investigador que vuelve su mirada indagatoria hacia aquella época. En esencia, el peronismo poseía una heterogeneidad y una complejidad mayores de lo que su propia imagen monolítica aparentaba, tanto en el aspecto social como en el aspecto institucional. ${ }^{31}$

La política educativa estuvo signada, a grandes rasgos, por una trama discursiva que apelaba a la necesidad de formar a los futuros ciudadanos en un conjunto de valores éticos y morales. La "Patria" no sólo demandaba ciudadanosconsumidores disciplinados para afrontar el mundo del trabajo. También debían

\footnotetext{
${ }^{29}$ NEIRBURG y PLOTKIN (2004), óp., cit, p. 15 y p. 231.

${ }^{30}$ GAGLIANO, Rafael (2003): "Consideraciones sobre la adolescencia en el período" en PUIGGRÓS Adriana (dirección) y CARLI Sandra (coordinadora tomo VI), Discursos pedagógicos e imaginario social en el peronismo (1945-1955), Buenos Aires, Galerna, p. 178.

${ }^{31}$ REIN, Raanan. (1998): Peronismo, populismo y política. Argentina 1943-1955, Buenos Aires, Editorial de Belgrano, p. 35.
} 
estar "físicamente y moralmente sanos" para conducir el país y defender la soberanía. Estas ideas se hallaban presentes en el poblacionismo argentino, en el cual se imbricaron los conceptos de población y raza encuadrados en un esquema nacionalista y conservador. ${ }^{32}$

Los discursos pedagógicos del peronismo incorporó parte de estas aspiraciones reseñadas. También convergieron en él las demandas de otros sectores: Ejército, Iglesia, clase obrera, socialistas, nacionalistas, conservadores, que apuntaron a la creación de un "Estado fuerte", es decir, un Estado interventor. Se apostó a un eclecticismo en el que se superponían el espiritualismo, el materialismo y el bienestar social junto con la educación religiosa.

Los pedagogos modeladores de la política educativa fueron Jorge Pedro Arizaga y Juan Cassani. Arizaga ocupó en 1946 el cargo de subsecretario de Instrucción Pública. Maestro nacional y profesor de educación física, impulsó la primera reforma del sistema educativo peronista implementada por el decreto $\mathrm{n}^{\circ} 26.944$ el 4 de octubre de 1947. Había participado en la reforma educativa de Manuel Fresco en la provincia de Buenos Aires y se destacó como secretario del Consejo Nacional de Educación. Consideraba que la corriente "normalista" junto con la ley 1420 había caducado. Influenciado por la postura educativa de Pestalozzi $^{33}$, el Plan de Arizaga propuso una nueva orientación en la cual se redefinía la labor docente en la escuela primaria para impartir planes y programas.

El principio básico era organizar el idioma y la historia nacional y vitalizar la escuela para la participación en la vida social y el mundo del trabajo. El lugar que debía ocupar la educación secundaria se reducía a la orientación espiritual del adolescente y a la formación de trabajadores y ciudadanos. Por su parte, la educación primaria debía ser depurada del atomizado positivismo y del escolasticismo que sólo reducían su inquietud a la simple transmisión de conocimientos $^{34}$. Su reforma contemplaba una enseñanza primaria formada

\footnotetext{
32 MIRANDA, Marisa. (2005): "La Biotipología en el pronatalismo argentino (19301983)”, en Asclepios, vol. LVII, pp 189-218.

${ }^{33}$ Johann Heinrich Pestalozzi (1746-1827) fue un pedagogo suizo para quien la educación del niño debía realizarse en plena armonía con la naturaleza. Conforme a esta idea, se desprende la necesidad de libertad en la educación del alumno a partir de la observación de las experiencias, intereses y actividades educativas. El punto de partida de la actividad intelectual y moral era para él la intuición, es decir, una aprehensión directa de los objetos exteriores. Bregaba por una "educación integral" -inteligencia, sentimientomoralidad- junto al desarrollo de la fortaleza física. BREGAZZI, Violeta y MANGANIELLO Ethel. (1996): Historia de la Educación, Buenos Aires, Librería del Colegio, pp. 190-202.

${ }^{34}$ ARIZAGA, Jorge. (1947):“Aplicación del Plan de Gobierno en la enseñanza Primaria”, en El Monitor, año LXVI, n 847-900, p. 36.
} 
por un primer ciclo optativo preescolar (4 y 5 años de edad), un segundo ciclo obligatorio de cinco años (6 a 11 años de edad), y un tercer ciclo de dos años (12 a 14 años de edad), llamado de aprendizaje general. Su finalidad era formar obreros especializados con nivel de oficiales. Este conjunto de innovaciones se vieron truncadas con la renuncia de Arizaga y la llegada de Ivanissevich al Ministerio de Educación.

El pedagogo Juan Cassani a finales del segundo gobierno de Perón se desempeñó como Director General de Enseñanza Secundaria, Media y Especial. Influenciado por el idealismo pedagógico del italiano Gentile, quien fuera ministro de educación de Benito Mussolini, Cassani estaba adscrito a la corriente antipositivista pedagógica combinando un liberalismo normalista con el irracionalismo espiritualista. El credo nacionalista-espiritualista y el antipositivismo pedagógico y la discusión entre existencialismo y tomismo se erigieron como núcleo de debate en el Congreso de Filosofía llevado a cabo en la ciudad de Mendoza en el año 1949. Uno de sus disertantes fue el propio Cassani. Al igual que Perón, Cassani le otorgaba un rol central al Estado, entendiendo que la cultura nacional derivaba de la misma repartición central para la creación de una pedagogía nativa. ${ }^{35}$

Las políticas educativas del peronismo estuvieron conducidas por tres ministros. Entre los años 1946-1948 estuvo a cargo de Belisario Gache Pirán, a la sazón ministro de Justicia e Instrucción Pública. Bajo su desempeño, Perón consiguió convertir en ley el decreto del año 1943 introduciendo la enseñanza católica en las escuelas. Su proyecto pedagógico estaba construido en base a una educación humanística, antimaterialista y racionalista.

Entre los años 1948-1950 la Secretaría de Educación -desde 1949 transformada en Ministerio-fue ocupada por el médico higienista y católico Oscar Ivanissevich. ${ }^{36}$ Interventor de la Universidad de Buenos Aires entre 1946 y 1949 era integrante del Instituto de Biotipología. ${ }^{37}$ Consideraba a las Fuerzas Armadas como garante del progreso del país con un discurso teñido de catolicismo. Poseía una visión organicista de la sociedad, en la cual los tópicos

\footnotetext{
35 Ibídem., p. 166.

${ }^{36}$ PLOTKIN. (1994): Op., cit, pp. 156-157.

${ }^{37}$ Creada en 1932 y denominada Asociación Argentina de Biotipología, Eugenesia y Medicina Social, estuvo integrada por figuras de renombre como el pedagogo Víctor Mercante, el escritor Gustavo Martínez Zuviría y el ministro de Educación de Perón, Oscar Ivanissevich. Su primer director fue el médico eugenista Arturo Rossi, quien impulsó en la provincia de Buenos Aires en el año 1933 la implementación de las fichas biotipológicas. Para un análisis sobre darwuinismo social y eugenesia en América Latina ver MIRANDA, Marisa y VALLEJO, Gustavo (compiladores). (2005): Darwinismo social y eugenesia en el mundo latino, Buenos Aires, Siglo XXI (Argentina).
} 
de patria, religión, familia y dios, se articulaban con elementos como Pueblo, Estado y Nación. El objetivo de la educación era enfatizar la importancia de los sentimientos por sobre los pensamientos e inculcar el respeto por las tradiciones del país, junto con tres valores fundamentales que se implementaron en los programas para las escuelas primarias en 1950: disciplina, piedad y nacionalismo. ${ }^{38}$ Según él, la universidad estaba destinada para un grupo minoritario; credo que se contradecía con la retórica social del peronismo. En 1950 fue obligado a renunciar a su cargo en teoría por una supuesta hostilidad que le profesaba Eva Perón. ${ }^{39}$

De 1950 hasta el derrocamiento del gobierno en 1955 el ministerio fue ocupado por Armando Méndez San Martín, personalidad del entorno de Eva Perón, masón e interventor de la Sociedad de Beneficencia y uno de los funcionarios más polémicos de la etapa peronista. Durante su administración se introdujeron las políticas de adoctrinamiento para maestros y alumnos aunque la gestión de Ivanissevich ya había mostrado signos de politización de los contenidos educativos con la introducción del libro Florecer para alumnos de primer grado. ${ }^{40}$

A partir del año 1952 el gobierno había comenzado a ajustar el cinturón ideológico en las instituciones políticas y en la sociedad civil. La muerte de Eva Perón y su posterior sacralización, el fallido golpe militar del año anterior y las dificultades del modelo económico condicionado por la nueva coyuntura internacional, determinaron una nueva intervención del Estado. La identificación de un enemigo ("la antipatria, la oligarquía") ya no eran notas discursivas. En este contexto, la politización de la escuela primaria con los manuales de texto y las directivas al personal en todos los niveles de la educación fue la consecuencia más inmediata de este proceso.

¿Formaba parte del proyecto peronista la centralización y homogeneización ideológica de la sociedad desde su arribo al poder o fue un golpe de timón producto de los acontecimientos acaecidos a partir del año 1951 y la sucesiva crisis del modelo? La visión que nos ofrece el historiador Raanan Rein es elocuente: el peronismo habría signado su desarrollo en una serie de etapas en la cual la peronización del sistema educativo constituía la "etapa posterior". En este período, los receptores del mensaje estatal ya estarían en condiciones materiales e intelectuales de absorber los mensajes doctrinarios del gobierno. ${ }^{41}$

\footnotetext{
${ }^{38}$ PLOTKIN, óp., cit, (1994), p. 165

${ }^{39}$ Ibidem, p. 170.

${ }^{40}$ CAIMARI (1995): óp., cit, p. 182.

${ }^{41}$ REIN. (1998), óp., cit, p. 89.
} 
En este anclaje analítico confluye la investigación de Mariano Plotkin para quien "centralización política" pareciera ser sinónimo de "politización educativa". Quizás podríamos arriesgar otra hipótesis basada en el siguiente argumento: debido a la crisis del modelo de redistribución estatal en la segunda presidencia de Perón, la distribución material fue reemplazada por una suerte de distribución simbólica sustentada en la formación de un imaginario social que santificó la imagen de Eva Perón, sacralizó la simbología peronista y resignificó la historia argentina. ${ }^{42}$

\section{El Plan Económico de 1952: Ahorro, denuncia y control ideológico}

Siguiendo los lineamientos del Segundo Plan Quinquenal especialmente el capítulo XXVIII -"Racionalización administrativa" - se aprobaron un conjunto de medidas tendientes a dicha racionalización. Los prolijos organigramas pautaban la "organización funcional administrativa" cuyo objetivo era facilitar "la conducción general" del país mediante la unidad de concepción del Gobierno y la unidad de acción del Estado." ${ }^{43}$ Uno de los puntos nodales para avanzar en esta política era el Plan de adoctrinamiento en los principios del "credo justicialista", la capacitación del personal de la administración pública mediante la enseñanza de conocimientos técnicos y la evaluación de condiciones para ingresar al sector.

En 1952 se puso en marcha el Plan Económico que tenía como eje el fomento del ahorro para contrarrestar la crisis por la cual transitaba el país en todos los ministerios dependientes del Estado. ${ }^{44}$ Perón pedía a la población practicar la austeridad en el consumo y tratar de eliminar los derroches innecesarios. Esta nueva orientación debía ser difundida en las escuelas y colegios de todo el territorio nacional.

Por medio del decreto $\mathrm{N}^{\mathrm{o}} 4.490$ el Poder Ejecutivo suprimió el sábado como día hábil escolar para la administración. Las causas invocadas son de

\footnotetext{
${ }^{42}$ No es mi intención trasladar esquemáticamente los principios de análisis que forjó la historiografía europea para explicar el fenómeno del fascismo en su versión italiana y alemana. GENTILE, Emilio. (2007): El culto del Littorio. La sacralización de la política en la Italia Fascista, Buenos Aires, Siglo XXI (Argentina); del mismo autor, La vía italiana al totalitarismo. Partido y Estado en el régimen fascista, Buenos Aires, Siglo XXI (Argentina), 2005. Las especificidades de la realidad argentinas hacia fines de 1940 difieren de la realidad europea con implicaciones sociales e imaginarios sustancialmente diferentes.

43 Segundo Plan Quinquenal, Presidencia de la Nación, Subsecretaria de Informaciones, 1953 , p. 320.

${ }^{44}$ El Ministerio de Salud a la sazón dirigido por Ramón Carrillo fue objeto de las mismas políticas de racionalización. RAMACCIOTTI. (2009): óp., cit, pp. 120-121.
} 
índole familiar: el niño y el joven se ven sustraídos del hogar impidiéndoles la compañía de sus padres y el consejo de los mismos. Como respuesta paliativa se decidió aumentar la jornada de labor docente de lunes a viernes, en diez y quince minutos para la enseñanza primaria y secundaria respectivamente. Se redujeron las horas de clase en cinco minutos para distribuir la jornada del sábado suprimido. En los Colegios Nacionales, Liceos de Señoritas y Escuelas Normales, se aumentaron en el turno de la mañana y de la tarde el número de clases por jornada pasaron de cinco a seis; disminuyendo la duración de cada clase de cuarenta y cinco minutos a cuarenta. ${ }^{45}$

El apoyo al Plan Económico buscaba obtener un mayor rendimiento de la labor del personal por medio de un conjunto de normas complementarias sin distinción de jerarquías: abstenerse de realizar llamadas telefónicas superfluas, evitar concurrir a la oficina con elementos impresos de carácter tendencioso y desconectar, al término de las tareas, todo artefacto o maquinaria eléctrica. Los útiles de oficina se entregarían bajo recibo mientras que los papeles o formularios en blanco, caídos en desuso, debían ser remitidos por las distintas reparticiones a la Dirección General de Administración, para ser recortados y aprovechados nuevamente. El no cumplimiento de estas disposiciones daría lugar a sanciones disciplinarias. ${ }^{46}$

El gobierno también instaba a la comunidad educativa para organizar la tarea docente sin que ello implicara la realización de gastos imprescindibles: los lápices, gomas y otros elementos debían utilizarse lo justo y necesario y se utilizaría los cuadernos de manera integral, sin dejar espacios en blanco. ${ }^{47}$

La exhortación al desarrollo de una sólida conciencia previsora se transformó en un proceso de educación individual que el gobierno relacionaba asiduamente "con los ideales de orden, trabajo y dignidad". Si bien la temática del ahorro no fue una novedad del peronismo - los manuales de lectura para el nivel primario en la década de 1930 dan cuenta de ello- a partir de la crisis del modelo entre los años 1951-1952 se estimuló una política concreta sobre el mismo. El Ministerio de Educación, de acuerdo a la política estatal, pregonó la necesidad de que tanto directivos como docentes e inspectores vigilaran en los establecimientos educativos el cumplimiento de las disposiciones que prescribían la obligatoriedad de la enseñanza y práctica del ahorro. ${ }^{48}$ Complementaria a esta medida, en

\footnotetext{
45 Boletín de Comunicaciones, Año IV, n 216, 11 de abril de 1952, pp. 190-191.

${ }^{46}$ Boletín de Comunicaciones, Año IV, n²23, 30 de mayo, pp.389-390.

47 Boletín de Comunicaciones, Año IV, ${ }^{\circ}$ 216, 11 de abril de 1952, pp. 196-197.

${ }^{48}$ Boletín de Comunicaciones, Año III, n ${ }^{\circ}$ 172, 8 de junio de 1951, p. 587.
} 
todos los establecimientos dependientes del organismo, se dictaron clases alusivas sobre el "Día del Seguro".

\section{Denunciar al "enemigo": las directivas del Ministro Armando Méndez San Martín}

En esta coyuntura, el ministro de Educación Armando Méndez San Martín, editorializaba en el Boletín una de las más audaces directivas en mayo de 1952. Por primera vez, aparecía publicada una extensa arenga en referencia a Juan Perón y Eva Perón. Se instaba a la persecución y a la censura. La editorial hacía referencia a "la situación política y social del país y sobre los medios de combatir la acción nefasta de la antipatria..." ${ }^{49}$ La arenga exalta la obra de la justicia social, la independencia económica y la soberanía política enjuiciando a los detractores del gobierno en la arena internacional, (léase EEUU):

... provoca una enconada oposición de los elementos ligados al capitalismo internacional, los que convencidos de la inutilidad de los esfuerzos que desarrollan para conseguir adeptos por medios lícitos, se dedican sistemáticamente a realizar una vil campaña de calumnias, mentiras y rumores tendenciosos, en el interior de la Nación, al propio tiempo que en el exterior se suman a las fuerzas del capitalismo internacional que les utiliza como vehículo para planear movimientos tendientes a lesionar a la República sus órganos vitales... ${ }^{50}$

Las directivas a seguir por parte de los establecimientos eran las siguientes:

1-Difundir la obra y la doctrina del justicialismo, señalando los fundamentos doctrinarios de la política social, económico-financiero e internacional del gobierno,

2-Rebatir toda versión tendenciosa sobre el estado actual del país, comentarios maliciosos, rumores infundados en particular en los ambientes educativos y culturales donde "la oposición hace circular diversos rumores tendenciosos...";

3- Individualizar sistemáticamente a quienes en las oficinas, sea personal de la administración o público asistente, pretenda promover desórdenes en mérito a críticas sobre el servicio o de hacer comentarios llamados de crítica constructiva o de cualquier tipo o hacer circular impresos u otros elementos que utiliza la oposición para sembrar el desorden y la anarquía; 4- Difundir, aprovechando toda oportunidad favorable en el hogar, en la calle, en el club, la obra patriótica y humanitaria de la benemérita

\footnotetext{
49 Boletín de Comunicaciones, Año IV, n ${ }^{\circ 222,} 23$ de mayo de 1952, pp. 365-367.

${ }^{50}$ Ibídem., p. 365.
}

Rev. hist. edu. latinoam. Vol. 15. Año 2010, pp. 63 - 92 
Fundación "Eva Perón", no permitiendo reflexiones que bajo la apariencia de crítica objetiva, únicamente tienen por finalidad afectar los nobles prestigios de dicha institución y denunciar de inmediato a la Superioridad o a las autoridades encargadas del orden, a las personas que se sorprendan en maniobras de oposición al régimen constituido, ya sea con actitudes o con comentarios malevolentes, críticas insidiosas, etc. ${ }^{51}$

El tono de la directiva rompía con los recursos estilísticos utilizados por el Boletín de Comunicaciones. Claramente, es una declaración de guerra contra un enemigo que podía materializar en cualquier sector de la sociedad. El llamado a la vigilancia y a la denuncia amedrentaba el cariz democrático del gobierno en el interregno 1946-1951. Los límites difusos entre una "crítica constructiva" y una "crítica insidiosa" quedaban bajo la tutela y la decisión final del Estado en cuanto que era una y que era la otra.

Armando Méndez San Martín reformó los programas de estudio de acuerdo a la orientación política del peronismo. En tren de citar un ejemplo, mencionaremos las orientaciones didácticas para los cursos de aplicación de las escuelas normales propuestas por la Dirección General de Enseñanza Secundaria, Especial, Normal y Superior. Se dividían en un programa básico de "Conocimientos" y un programa de "Desenvolvimiento" y "Unidades de Trabajo" destacándose el "cultivo del idioma", la formación del "sentimiento estético", las "manualidades" y las "danzas populares".

El conjunto de aprendizajes apuntaba a una finalidad social-educativa. Las "Unidades de Trabajo" comprendían tópicos relacionados con dicha temática: "La alimentación", "La Salud", "La vivienda", "Los beneficios sociales del obrero", "La dignificación de la mujer", "Los Derechos de la familia-del trabajador-de la ancianidad y de la educación y de la cultura". En resumen, los contenidos no eran novedosos en si mismos, sino que albergaban el espíritu de la Constitución Reformada del año 1949. Por último, la nueva didáctica apuntaba a la formación del sentimiento nacional y patriótico en las aulas. ${ }^{52}$

\footnotetext{
${ }^{51}$ Ibídem., pp. 366-367.

${ }^{52}$ La educación y formación de la conciencia histórica en la educación primaria resultó primordial para el peronismo. Esto explica porque el adoctrinamiento difirió entre el nivel primario y el secundario. Mientras que en el primero se implementaron los "manuales de textos peronizados" en el segundo, los manuales mantenían cierta continuidad en cuanto a contenidos con las décadas anteriores. Así las cosas, los mecanismos de "socialización" en la doctrina justicialista funcionaron de manera diferente en el ciclo secundario. Esta temática no fue abordada en profundidad por los historiadores ya que pareciera resultar más atractivo demostrar con fuentes concretas - como los pintorescos manuales de lectura- el "poder avasallador del peronismo" en el espacio escolar.
} 
El nuevo Plan de Estudios aplicado a partir de marzo de 1953 favorecía "al conocimiento de la Nueva Argentina como asignatura independiente en el ciclo básico y en el primer ciclo de las escuelas nacionales de comercio, escuelas normales y el segundo ciclo del Bachillerato." ${ }^{53}$

\section{Las peticiones de la comunidad educativa al Ministerio}

La centralización implicaba la intervención regular del Ministerio en todos los aspectos concernientes a las demandas de la comunidad educativa. Más allá de calibrar los mecanismos institucionales por medio del cual funcionaba la maquinaria administrativa; el orden burocrático-educativo también intervenía en la delegación o resolución de conflictos que surgían entre los distintos actores del sistema de enseñanza.

El Ministerio se transformó en una suerte de árbitro que, a corto plazo, dictaminaba su decisión a favor o en contra del peticionante o delegaba decisiones que recaían en las rectorías de los colegios. La formulación de pedidos abarca un amplio abanico de temáticas. Asimismo, las notas fueron extraídas del archivo de un Colegio Nacional que, como destacamos en la introducción, fue fundado por el peronismo en el distrito de Morón hacia el año 1949.

La falta de "asientos" necesarios para cubrir la gran demanda de los aspirantes al primer año fue uno de los problemas que debió afrontar el Ministerio de Educación. Numerosos pedidos redactados por padres de adolescentes reclaman un "asiento", es decir, una vacante en un colegio secundario público. En esta dirección consideramos que el Estado se vio sobrepasado por las aspiraciones de los jóvenes que anhelaban seguir sus estudios secundarios y que dicha demanda es anterior a la génesis del peronismo. ${ }^{54}$ La problemática era reconocida por el Boletín de Comunicaciones. Hacia el año 1954, el gobierno encargó a una comisión de funcionarios técnicos la planificación y racionalización de las necesidades de la población escolar en la enseñanza media radicada en Capital Federal y el gran Buenos Aires. La resolución recomendaba que si fuera necesario los institutos privados de enseñanza laicos incorporen una mayor población escolar. ${ }^{55}$

¿Por qué razón se dejaba de lado en dicha resolución a los institutos privados religiosos? Sólo podemos orquestar una hipótesis teniendo en cuenta la relación

\footnotetext{
${ }^{53}$ Boletín de Comunicaciones, Año IV, nº252, 19 de diciembre de 1952, pp. 1269-1273.

${ }^{54}$ CAMMAROTA, Adrián. (2008): "La educación media bajo el peronismo: 19461955", tesis de maestría dirigida por la Dra. Carolina Biernat, Universidad Nacional Tres de Febrero.

${ }^{55}$ Boletín de Comunicaciones, Año V, n 328,4 de junio de 1954, p. 408.
} 
tejida entre el gobierno y la Iglesia Católica en esta etapa,-relaciones sumamente idílicas en la génesis del movimiento-transfigurada en un sutil cálculo político por parte de Perón. No obstante, la armonía fue confluyendo en un sensible resquebrajamiento asumiendo un carácter de abierto conflicto hacia 1954. En sintonía con el contexto descripto. ¿Se evitaría con la resolución citada intentar resolver el problema de la capacidad edilicia sin "democratizar" un espacio signado por la selección evitando, al mismo tiempo, abrir un nuevo frente de confrontación con la alta jerarquía eclesiástica? Que el peronismo llamó a la necesidad de democratizar la educación privada no quedan interrogantes en esa dirección. A fines de su segundo mandato, Perón interpeló a los institutos privados para incorporar a los "hijos de obreros" en su matrícula.

En otras ocasiones, las vías de reclamos transitaban por una camino inverso: autoridades del Colegio/Superioridad inmediata. En el caso mencionado a continuación veremos como la Dirección General de Enseñanza podía actuar de oficio para resolver cuestiones de índoles particulares. Este organismo poseía la atribución de "recalificar" exámenes, a juzgar por el siguiente caso en el cual una estudiante había sido aplazada en el examen de Castellano con una calificación de 2 (dos) "por la actitud injusta y parcial de una profesora" en diciembre de 1953. La queja fue presentada por el padre de la alumna Nelly M. ${ }^{56}$, estudiante de la escuela Normal Nacional Mixta de Lomas de Zamora el 17 de noviembre de $1954^{57}$. El Colegio trasladó el reclamo a la superioridad inmediata. En este caso llama la atención la sustancial actuación del Ministerio de Educación a través de la Dirección General de Enseñanza Secundaria. La petición del padre fue analizada minuciosamente siendo que la Dirección General de Enseñanza Secundaria. Esta dirección examinó la evaluación de la alumna en un memorandun que fue a su vez elevado al Ministro de Educación. Es una versión mecanografiada en la cual "prescindiendo del lápiz rojo de las profesoras" se analizó con detenimiento la ortografía, el vocabulario, la interpretación y el desarrollo del texto y la presentación del trabajo. En búsqueda de una mejor "objetividad" la evaluación de la alumna fue cotejada con las de las compañeras, según reza el informe. Y las conclusiones de los mismos son elocuentes: "puede advertirse que no ha habido unidad de criterio en la apreciación del examen". Estima que la calificación de la alumna debió ser de cinco puntos no de dos. ${ }^{58}$

\footnotetext{
${ }^{56}$ La adolescente luego ingresaría al Colegio Nacional de Morón. La nota fue extraída de su legajo.

${ }^{57}$ Carta del padre de la alumna, 17 de noviembre de 1954. Archivo del ex Colegio Nacional de Morón.

${ }^{58}$ Memorandun dirigido al Ministro de Educación. Archivo del ex Colegio Nacional de Morón.
} 
Si los canales formales de reclamo eran los más utilizados por los peticionantes, veremos que, paralelamente, se utilizaban otros menos institucionalizados. Estos apelaban directamente a la benevolencia particular de uno de los más distinguidos símbolos del gobierno: Eva Perón. Fechada el 13 de marzo de 1950, "Año del Libertador Gral. Don José de San Martín” y dirigida a la Fundación Eva Perón; la nota comenzaba invocando a la benevolencia de Eva. A renglón seguido el estudiante describe su situación: destaca que tiene 17 años y que terminada la esuela primaria comenzó a trabajar para ayudar en "la subsistencia del hogar". Que el año anterior “... impulsado por el noble propósito de estudiar más para servir mejor a la Patria comencé mis estudios en el Colegio Nacional de Morón."59 Asimismo, se había preparado para rendir en categoría de libre las materias del segundo año. A causa de su trabajo, no estuvo en condiciones de preparar todas las asignaturas, quedando aplazado en dos de ellas: Matemáticas y latín. Esta situación le restaba la posibilidad de acceder al curso inmediato. Solicita a Eva Perón que interceda ante el Ministro de Educación, Oscar Ivanissevich para darle una "solución satisfactoria a su caso" confiando que en su condición de trabajador podrá obtener ese beneficio.

Siguiendo la vía burocrática, la Secretaría Técnica, dependiente de la Dirección General de Enseñanza Secundaria, Normal y Especial pasó el informe al Rectorado del Colegio Nacional "con la recomendación de urgente despacho" el día tres de mayo. Tres días después, la rectoría del Colegio informó al inspector de dicha secretaria, que el alumno había sido promovido al tercer año en virtud de la Resolución Ministerial del 14 de marzo, la cual otorgaba la posibilidad-siempre a consideración de las autoridades del Colegio-de promover el año con dos o más materias previas. ${ }^{60}$

En resumen: en un clima de demandas sociales y construcción del poder legitimante basado en la lógica de la "justicia social" y en la centralización de los poderes públicos y políticos, el Estado debía otorgar un margen de flexibilidad en el seno de sus instituciones con el fin de captar voluntades. Accionando dentro de esta perspectiva, la atención a los reclamos que emergían de la sociedad

\footnotetext{
${ }^{59}$ Carta de un alumno, I. M., Ituzaingó, 13/3/1950. Archivo del ex Colegio Nacional de Morón.

${ }^{60}$ Esta Resolución Ministerial autorizaba a los establecimientos Secundarios, Normales, Especiales y Técnicos a recibir solicitudes de alumnos que aspiraban a ser promovidos con dos o más materias. El estudio de las razones que pueden justificar la excepción correspondía a los profesores del curso al que el alumno perteneció y al Rector del Establecimiento respectivo. Boletín de Comunicaciones, Año II, $\mathrm{n}^{\circ}$ 107, 17 de marzo de 1950.
} 
civil suponían la atracción de una noción de ciudadanía por fuera del molde específicamente político y redefinida en un molde social. ${ }^{61}$ La consecuente lógica de la justicia distributiva y la redefinición del concepto de ciudadanía abrieron la compuerta a los reclamos y demandas de la sociedad civil. Así, este sector obtuvo resultados muchos más satisfactorios a diferencia de las décadas precedentes. Subrepticiamente, la intervención y resolución de conflictos generaba una peculiar forma de legitimación burocrática, autoafirmando el poder de la repartición central por encima de las instituciones educativas provinciales.

\section{La relación Estado-docentes: control ideológico, centralización y derechos}

La centralización del sistema educativo tuvo su mayor implicancia en la relación docentes-Estado. El peronismo se ocupó de las necesidades de los docentes inmediatamente después de tomar el poder con una clara tendencia reglamerantista y ordenancista del campo técnico profesional. Así, el Poder Ejecutivo sancionó en 1954 el "Estatuto del docente argentino del Gral Perón" que alcanzó a todos los docentes nacionales exceptuando el personal contratado por el Ministerio. Para ingresar a la carrera se requería ser ciudadano argentino y poseer el pleno dominio del idioma nacional. Para ser nombrado profesor era menester poseer título habilitante expedido por los institutos oficiales del profesorado de la Nación.

Entre los derechos que se les otorgaban a los trabajadores estaban aquellos que comprendían la percepción de sueldos, haberes jubilatorios, suplementos y bonificaciones, vacaciones anuales, asistencia social, libertad de agremiación y el perfeccionamiento por medio de becas. ${ }^{62}$ En sus orígenes, un cargo suplente podía ser cubierto gracias a la designación del rector de los Colegios mientras que las vacantes titulares y provisionales eran jurisdicción del Ministerio de

\footnotetext{
${ }^{61}$ Según el historiador Daniel James "El atractivo político fundamental del peronismo reside en su capacidad para redefinir la noción de ciudadanía dentro de un contexto más amplio, esencialmente social. La cuestión de la ciudadanía en sí misma, y la del acceso a la plenitud de los derechos políticos, fue un aspecto poderoso del discurso peronista, donde formó parte de un lenguaje de protesta, de gran resonancia popular, frente a la exclusión política (...)" "La ciudadanía ya no debía ser definida más simplemente en función de derechos individuales y relaciones dentro de la sociedad política, sino redefinida en función de la esfera económica y social de la sociedad civil” JAMES, Daniel. (2006): Resistencia e Integración. El peronismo y la clase trabajadora argentina, 1946-1976, Buenos Aires, Siglo XXI (Argentina), p. 27.

${ }^{62}$ BERNETTI Jorge Luis y PUIGGRÓS, Adriana. (2001): "Los discursos de los docentes y la organización del campo técnico profesional" en Adriana Puiggrós (dirección), Peronismo: Cultura política y educación (1945-1955), Buenos Aires, Galerna, pp. 207-208.
} 
Educación Nacional. Esta situación fue trastocada con la creación del registro de suplentes y provisorios en el año 1952. El aspirante a la carrera docente se anotaba en dicho organismo y en base a sus antecedentes y título de base obtenía un puntaje que le confería un lugar determinado en el listado. Al generarse una vacante en las escuelas y Colegios de jurisdicción nacional, el Ministerio de Educación ofrecía el cargo en cuestión por orden de merito. El profesor/ra designado recibía en su domicilio la citación, en la cual se estipulaba el destino laboral, la carga horaria y la situación de revista.

En virtud del amplio conjunto de normativas establecidas que apuntaban a la profesionalización de la carrera docente el gobierno aseguró los ascensos del personal directivo y técnico-docente. En 1950 se creó la Junta de Calificación de Enseñanza Establecía un régimen de normas para asegurar "ecuánimemente" los ascensos del personal directivo y técnico-docente, teniendo en cuenta los méritos y condiciones de los postulantes ${ }^{63}$. Las vacantes serían cubiertas por un concurso de oposición y las condiciones de los candidatos. El dictamen sobre sus meritos recaería en la Junta de Clasificación integrada por tres Directores Generales de Enseñanza (de Primaria, Secundaria y Técnica) y por tres delegados propuestos por la entidad gremial reconocida oficialmente. La Junta de Calificación estaba en condiciones de solicitar toda clase de información al Ministerio y proponía los nombres y cargos de los elegidos como candidatos para llenar las vacantes existentes. Luego, se expedía sobre las condiciones personales, aptitudes técnicas, experiencia didáctica, cultura general de los candidatos, antigüedad en la docencia y demás "circunstancias aclaratorias". El dictamen era elevado al Ministerio para su consideración final. Es decir, la Junta de Calificación sólo realizaba una preselección de los aspirantes pero, la decisión final para la designación era jurisdicción del Ministerio de Educación.

Institucionalmente este mecanismo burocrático poseía en la práctica una doble cara. Por un lado, se democratizaba el sistema de ascenso social en base a los méritos y desempeños del postulante quedando relegados los ascensos por favoritismos, ya sean por lealtades políticas o de otro tipo. Por el otro, el hecho concreto de que la decisión final sobre las designaciones recaía en el Ministerio de Educación Nacional pone en tela de juicio el aspecto mencionado anteriormente. El Ministerio de Educación era un organismo político que debía actuar de manera consecuente con los postulados del gobierno justicialista. Un claro ejemplo de ello es la falta de continuidad en el ejecutivo del Ministerio: desde el año 1946 ocuparon

${ }^{63}$ Boletín de Comunicaciones, Año II, $\mathrm{n}^{\circ} 147,15$ de diciembre de 1950, pp. 14571458 .

Rev. hist. edu. latinoam. Vol. 15. Año 2010, pp. 63 - 92 
la cartera tres ministros diferentes. ¿Se debía esta situación a la inhabilidad de estos ministros por reajustarse a las circunstancias cambiantes de un gobierno cuya característica principal era poseer una visión ecléctica de la realidad circundante que lo conducía a "fugar hacia delante" buscando nuevos posicionamientos y consensos en materia política? Sólo un ministro de notoria relevancia mantuvo su continuidad hasta un año antes de ser derrocado el peronismo: Ramón Carrillo quien a la sazón dirigía el Ministerio de Salud.

Para su funcionamiento, el orden burocrático-educativo generaba canales de comunicación y democratización pero, a su vez, mecanismos de control en las bases del sistema que apuntaban a la eficacia y a la regulación social. ¿Cómo se obtenía la información necesaria para que el Ministerio pudiera evaluar las capacidades del aspirante? El desempeño docente era relevado anualmente por las autoridades de los establecimientos. Según lo establecido por la Resolución Ministerial del 15 de mayo de 1953 se proveyeron Fichas de Conceptos las cuales debían ser completadas a máquina. La evaluación consistía en una serie de ítems que el Rector estaba en condiciones de evaluar y fundamentar. Los mismos eran: Cultura, Concepto Sintético, Preparación Científica Técnica; Aptitudes Docente y disciplinarias, espíritu de colaboración, Resultado de la Enseñanza, Asistencia y puntualidad y finalmente, Clasificación sintética general. El encargado de presentar esta información debidamente fundada a la Inspección General eran los inspectores de turno del Colegio. ${ }^{64}$

Una de las prácticas que realizaban las instituciones educativas para obtener información sobre el desempeño del plantel docente residía en la observación de clases. El Rector o Vicedirector se apersonaba en la cátedra y tomaba nota sobre la dote intelectual del educador, el aspecto pedagógico y disciplinario. La observación quedaba plasmada en un informe y posteriormente los datos relevados eran utilizados para completar las Fichas de Conceptos.

¿A qué apuntaban en la práctica estas evaluaciones? ¿Funcionaba como mecanismos de control, inclusión y exclusión dentro del circuito del campo educativo? Resulta sugestivo que este sistema haya sido aplicado en el año 1953, cuando los mecanismos de control del gobierno sobre las instituciones se asentaron en una suerte de verticalismo ideológico. Pero nos sería más fácil hallar las respuestas del porque se implementaron estas evaluaciones si echamos una mirada a la organización estatal de la época, caracterizada por la estratificación y la supuesta neutralidad de las burocracias estatales. Como ha planteado la historiadora Patricia Berrotarán, la carrera administrativa y los sistemas de premios sustentaron

\footnotetext{
${ }^{64}$ Las fichas de conceptos fueron extraídas del Archivo del ex Colegio Nacional de
} Morón. 
una jerarquización del personal desde los nuevos sistemas de valores de la administración implementados por el peronismo pero, al mismo tiempo, la formación de un cuerpo "científico y apolítico" operó sobre los sectores opositores asumiendo un control coactivo por los organismos de supervisión ${ }^{65}$. Lo expuesto por la autora en cuanto a que las estrategias de las políticas administrativas se transformaron en instrumentos de control ideológico político de los funcionarios, puede trasladarse al sistema de jerarquización docente descrito anteriormente. ${ }^{66}$

\section{CONCLUSIONES}

La creación del Ministerio de Educación de la Nación en 1949 se produjo en un contexto de modernización estatal, centralización y democratización de la educación. El proceso de centralización educativa había despuntado a fines del siglo XIX. Con la estructuración del Ministerio culminó el proceso reseñado signado, a su vez, por la necesitad de terminar con el analfabetismo y democratizar el ciclo secundario del sistema y los estudios universitarios.

Los resultados de este proceso no fueron para nada desdeñables ya que se fundaron Colegios Nacionales y Escuelas Normales, Liceos de Señoritas y Escuelas Industriales aumentando, considerable, la matrícula pos primaria. Pero la centralización confluyó - a partir del año 1951-1952- en una suerte de profundización y homogeneización ideológica en la cual la llamada "Doctrina Justicialista" estuvo entroncada con los lineamientos del Segundo Plan Quinquenal.

Con el fin de construir una "pedagogía nacional" se diseñaron nuevos programas imbuidos en la ideología de una "educación integral" (conocimientos intelectuales y educación espiritual). En este espacio, los discursos pedagógicos del peronismo no constituyeron una novedad en sí misma. Se inscribieron en una continuidad de ideas con las concepciones imperantes en las décadas anteriores: la concepción de una "raza fuerte y disciplinada" -principios derivados de los postulados eugenésicos-, aunada a una educación integral que se oponía al corpus pedagógico de raigambre positivista.

Durante la gestión del ministro Armando Méndez San Martín el sistema educativo atravesó un proceso denominado como "peronización". Abrevando en un nacionalismo cuasi sacro, la liturgia peronista incorporó con abnegación el culto a la patria asociándolo, a su vez, a los símbolos del justicialismo. Se elaboró una nueva versión de la historia nacional en la cual el "primer trabajador" o

\footnotetext{
65 BERROTARÄN. (2004): op., cit, p. 39

${ }^{66}$ Para los funcionarios del Ministerio de Educación también se proveyeron fichas de conceptos con el fin de aumentar la "productividad" por medio de incentivos monetarios.
} 
"primer pedagogo"( Perón), emergía como el conductor de una "Nueva Argentina" y cuya talla heroica era válida de comparación con las figuras de los héroes de la independencia como San Martín o Belgrano.

En un nivel general, todos los Ministerios del Estado se vieron abocados a estimular un conjunto de medidas tendientes a lograr una mayor racionalización administrativa y un mayor control de la burocracia, de acuerdo a los lineamientos del Plan de Austeridad implementado en 1952. Nos preguntamos si esta cuestión no sería un punto nodal para bosquejar una respuesta a la politización e ideologización del sistema. El trinomio crisis económica, racionalización y politización educativa, pareciera constituir un engranaje difícil de desbrozar uno de otro. Podemos aventurar -por fuera de las visiones historiográficas que incorporaron la idea de un régimen originario en 1946-, que la disminución de la distribución material característica del primer mandato fue reemplazada por una suerte de distribución simbólica en aras de no erosionar la legitimidad obtenida en la génesis del movimiento. Esto acarreó la introducción de un conjunto de prácticas nocivas características de un "régimen", sustentado en la simbología, la inquebrantable voluntad del líder, la propaganda, el adoctrinamiento y la represión ideológica.

El orden burocrático-educativo también intervenía en la delegación o resolución de conflictos que surgían entre los distintos actores del sistema de enseñanza, autolegitimándose por fuera de los poderes provinciales y ejerciendo a su vez el contralor del sistema de instrucción a nivel nacional. La peculiar intervención no permanecía ajena a la peregrinación de peticiones o demandas por parte de los integrantes del sistema de enseñanza. Se afirmaba así el primado de una política educativa que buscaba la construcción de una pedagogía nacional sustentada, en lo posible, en el aval de los distintos actores del sistema. Este modo de accionar no puede disociarse del contexto, de la originalidad del fenómeno del peronismo y de su vitalidad originaria: la refundación de la noción del concepto de ciudadanía como apropiadamente ha destacado el historiador Daniel James.

Una de las problemáticas más acuciantes que afrontó el Ministerio fue responder a la demanda edilicia para satisfacer las necesidades de los adolescentes que aspiraban seguir sus estudios secundarios. Las instituciones educativas fueron comprometidas en la coyuntura de ahorro supeditándose, por pedido del propio ministro Armando Méndez San Martín, a un clima de denuncia y silenciamiento de las "criticas insidiosas". En todas las instituciones dependientes del Estado la lógica de planificación, control ideológico y racionalización económica se instruyeron en paralelo al otorgamiento de un conjunto de derechos en materia laboral. En resumen: la medición y la predicción formaba parte de la obsesión por otorgarle a la organización estatal un marco cuantitativo, que a futuro permitiría corregir o avalar 
políticas gubernamentales reproduciéndose, en todos los niveles del funcionamiento institucional. Todo podía ser medido, cuantificado, o corregido, en aras de generar una mayor organicidad de las instituciones dependientes del Estado. Las reformas administrativas y el atolladero de medidas burocráticas apuntaban en esa dirección.

\section{FUENTES}

\section{ARCHIVO DEL EX COLEGIO NACIONAL DE MORÓN.}

MINISTERIO DE EDUCACIÓN, Boletín de Comunicaciones 1949-1955.

MINISTERIO DE EDUCACIÓN, Enseñanza Media 1914-1963, Departamento de Estadística Educativa. Tomo 1.

Segundo Plan Quinquenal, Presidencia de la Nación, Subsecretaria de Informaciones, 1953.

\section{REFERENCIAS}

ACHA, Omar. (2004): “Sociedad civil y sociedad política durante el primer peronismo", en Desarrollo Económico, vol. 44, julio-septiembre.

BERNETTI Jorge Luis y PUIGGRÓS, Adriana. (2001): "Los discursos de los docentes y la organización del campo técnico profesional" en: PUIGGRÓS, Adriana (dirección), Peronismo: Cultura política y educación (1945-1955), Buenos Aires, Galerna.

BERROTARÁN, Patricia. (2004): "La planificación como instrumento: políticas y organización en el estado peronista" (1946-1949)", en: BERROTARÁN, Patricia,

JÁUREGUI, Aníbal y ROUGIER, Marcelo: Sueños de Bienestar en la Nueva Argentina. Estado y Políticas Públicas durante el peronismo (1946-1955), Buenos Aires, Imago Mundi.

BERTONI, Lilia Ana. (2001): Patriotas, cosmopolitas y nacionalistas. La construcción de la nacionalidad argentina a fines del siglo XIX, Buenos Aires, Fondo de Cultura Económica.

BIANCHI, Susana. (1996):“Catolicismo y peronismo: la educación como campo de conflicto”, en Anuario del Instituto de Estudios Históricos-Sociales, ${ }^{\circ} 11$.

CAIMARI, Lila. (1995): Perón y la Iglesia Católica. Religión, Estado y sociedad en la Argentina, 1943-1955, Buenos Aires, Ariel.

GAGLIANO, Rafael (2003): "Consideraciones sobre la adolescencia en el período" en: PUIGGRÒS, Adriana (dirección) y CARLI, Sandra (coordinadora tomo VI), Discursos pedagógicos e imaginario social en el peronismo (1945-1955), Buenos Aires, Galerna.

GENTILE, Emilio. (2007): El culto del Littorio. La sacralización de la política en la Italia Fascista, Buenos Aires, Siglo XXI (Argentina).

GUEVARA, Raúl. (2006): Jurisdicción Transfederal. La leyenda de la ley 1420 y otros mitos porteños en educación, Buenos Aires, Universidad Nacional de Lomas de Zamora.

GONZALEZ BOLLO, Hernán. (2007): "Paradojas de la capacidad estatal bajo el peronismo: la 
centralización estadística y el Cuarto Censo Nacional, entre el caos burocrático y la manipulación de datos, 1943-1947”. Ponencia presentada en las XI Jornadas Interescuelas/ Departamento de Historia. Tucumán, 19 al 22 de septiembre.

GVIRTZ Silvina, (1999):“La politización de los contenidos escolares y la respuesta de los docentes primarios en los primeros gobiernos de Perón- Argentina 1949-1955”, en: Estudios Interdisciplinarios de América Latina y el Caribe, volumen 10, $\mathrm{n}^{\circ}$ 1, enero-junio.

JAMES, Daniel (2006): Resistencia e Integración. El peronismo y la clase trabajadora argentina, 1946-1976, Buenos Aires, Siglo XXI (Argentina).

PASTORIZA, Elisa y TORRE Juan Carlos. (2002): "La democratización del bienestar" en Torre Juan Carlos (dirección), Nueva Historia Argentina. Los años peronistas (1943-1955), Buenos Aires, Colección Nueva Historia Argentina, Sudamérica.

MIRANDA, Marisa y VALLEJO, Gustavo (compiladores) (2005): Darwinismo social y eugenesia en el mundo latino, Buenos Aires, Siglo XXI.

MIRANDA, Marisa. (2005): “La Biotipología en el pronatalismo argentino (1930-1983)”, en Asclepio, vol. LVII.

NEIUBURG, Federico y PLOTKIN, Mariano (compiladores). (2004): Intelectuales y expertos. La constitución del conocimiento social en la Argentina, Buenos Aires, Paidós.

OTERO, Hernán. (2006): Estadística y Nación. Una historia conceptual del pensamiento censal de la Argentina moderna 1868-1914, Buenos Aires, Prometeo.

PLOTKIN, Mariano. (1994). Mañana es San Perón: Propaganda, rituales políticos y educación en el régimen peronista. Buenos Aires, Ariel.

PUIGRRÓS, Adriana (dirección) y Edgardo Ossanna (dirección tomo VII) (1993): Historia de la educación Argentina, volumen V, Buenos Aires, Galerna.

RAMACCIOTTI, Karina. (2009): La política sanitaria del peronismo, Buenos Aires, Biblos.

REIN, Raanan. (1998): Peronismo, populismo y política. Argentina 1943-1955, Buenos Aires, Editorial de Belgrano.

TEDESCO Juan Carlos. (2009): Educación y sociedad en la Argentina (1880-1945), Buenos Aires, Siglo XXI.

WAINERMAN Catalina y HEREDIA, Mariana. (1998): ¿Mamá amasa la masa? Cien años en los libros de lectura de la escuela primaria, Buenos Aires, Editorial Belgrano.

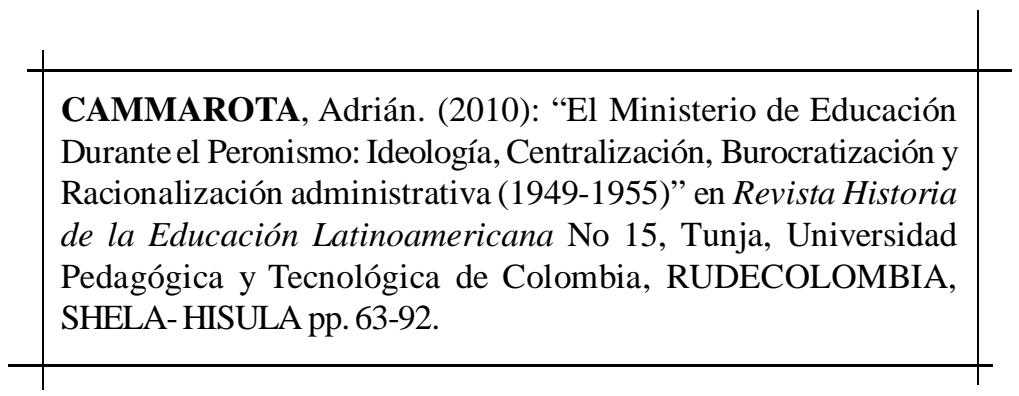

Rev. hist. edu. latinoam. Vol. 15. Año 2010, pp. 63 - 92 